\title{
Learning Difficulties and Working Memory Deficits among Primary School Students in Jakarta, Indonesia
}

\author{
Tjhin Wiguna', Noorhana Setyawati WR', Fransiska Kaligis', Myron L. Belfer ${ }^{2}$ \\ 'Department of Psychiatry, Faculty of Medicine University of Indonesia, Cipto Mangunkusumo General Hospital, Jakarta, Indonesia, \\ ${ }^{2}$ Population Health and Social Medicine, Harvard Medical School, Boston, MA, USA
}

\begin{abstract}
Objective: There are multiple possible etiologies for learning difficulties in children. There is growing evidence that many students identified as having learning difficulties have significant working memory deficits. To determine, in a sample of primary school students in Jakarta, Indonesia, the prevalence of learning difficulties and learning difficulties co-morbid with working memory deficits.

Methods: Subjects ( $\mathrm{N}=423$ ) were recruited via proportional random sampling from 27 primary schools. The first stage was a cross-sectional study of these students, while the second stage was a case-control study comparing all students with learning difficulties and working memory deficits with controls matched by school type, grade level, and gender.

Results: Among the students, whose mean age was 9.34 years (1.78), 13.7\% had a learning difficulty, while $8.04 \%$ had a learning difficulty with working memory deficit. The odds ratio of comorbid working memory deficit (in the face of a learning difficulty) was $7.0\left(x^{2}=35.96, p<0.001\right)$.

Conclusion: Learning difficulties and comorbid working memory deficits were relatively common among primary school students. Efforts should be made to identify these students and provide timely assistance, in order to optimize their educational success and mental health outcomes.
\end{abstract}

KEY WORDS: Learning difficulties; Working memory; Primary school; Student.

\section{INTRODUCTION}

Multiple brain processes are involved in learning, such that disruptions in any one process may result in a learning difficulty. ${ }^{1,2)}$ Mental health professionals are often involved in caring for children and adolescents with learning difficulties, given the significant impact that these conditions have on academic achievement, self-esteem, and overall functioning. While there appear to be differences (across countries) in the prevalence rates of learning difficulties, these conditions are among the most prevalent of mental health problems in children. For example, in the United States of America, the prevalence rate of all learning difficulties among school-age children is approximately $6-10 \%{ }^{3)}$ Unfortunately, there is no valid data on learning difficulty prevalence in Indonesia, one of the

\footnotetext{
Received: March 9, 2012 / Revised: April 12, 2012

Accepted: May 11, 2012

Address for correspondence: Tjhin Wiguna, M. Int $\mathrm{MH}$

Department of Psychiatry, University of Indonesia, Jl. Salemba

Raya 4, Jakarta 10430, Indonesia

Tel: +62-213107741, Fax: +62-2139899128

E-mail: twiga00@yahoo.com
}

most populous nations in the world.

Learning diffculties are defined as a significant discrepancy-not otherwise explained by physical or sensory impairments-between the child's intellectual functioning and academic performance. ${ }^{3-6)}$ While several studies have identified genetic factors, sensorimotor system integration impairments, and prematurity as risk factors for learning disorders, there is no single known cause.

Recent studies have focused on the role of working memory in learning difficulties. ${ }^{6-8)}$ These studies have found that (1) working memory is an important predictor of learning ability, and (2) working memory assessment can be helpful in determining learning capability; perhaps more so than the intelligence quotient (IQ) scores, which only indicate intelligence level. ${ }^{8,9)}$

Working memory is the ability to store and manipulate information within a short time period. It enables one to pay attention, remember, and act according to immediately received information. In contrast to short term memory, working memory requires information storing and processing ability, while short term memory only requires information retention. Working memory is an important 
component of executive functioning and is believed to be fundamental to problem solving. ${ }^{10)}$ Thus, working memory is essential to the acquisition of new knowledge and skills. Anatomically, working memory is regulated by the frontal lobe. ${ }^{8,9)}$

Working memory is essential to optimal completion of classroom activities, including those that require memorization of instructions and those that require information processing and endurance. ${ }^{8-10)}$ Children with working memory deficit may have poor attention and easy distractibility (not necessarily with hyperactivity) and low academic performance in relation to their peers. ${ }^{9-11)}$ They are at risk for dropping out of school prematurely and failing to achieve their potential in life. ${ }^{12)}$

Alloway et $a l .{ }^{9)}$ stated that intelligence and memory are two important components of learning. As reviewed, many studies have shown that, at the age of 5 years, working memory may be a better predictor of learning capability in the next 6 years and beyond, than intelligence. Olive $^{13)}$ mentioned that the limitation of working memory affected the ability to read because of the lack ofsynchonization between maintaning and processing information.

Wiguna et al. ${ }^{14)}$ in a pilot study of elementary students at a Child Development and Child Psychiatry Outpatient Clinic, identified $28 \%$ of the children as having a learning difficulty but did not differentiate whether or not they had any working memory deficit. In a study led by Durham University, $10 \%$ of 3,000 children had working memory deficit problems that seriously impacted learning capability. $^{10)}$

Up to this point, studies on the relationship between intelligence level and academic achievement have not definitively indicated the optimal management of learning difficulties because working memory function has not been considered. For example, during writing, visual working memory plays an important role as it stores the orthographic information of already written words, as an aid to catching spelling, or other errors and also represents the physical layout of the text. If there is any insufficiency in working memory function, these children have a slower and more laborious writing process. ${ }^{15,16)}$

Therefore, aims of this study were (1) to identify the proportion of primary school students who had both a learning difficulty and working memory deficit; (2) to determine the odds ratio of working memory among students with learning difficulty.

\section{METHODS}

This was a two stage study. The first stage was a cross sectional study $(n=423)$ which tried to identify the proportion of student with co-morbidty between learning difficulty and working memory deficit. Children with learning difficulty were defined as children with a discrepancy between their intellectual functioning and academic achievement which could not be explained otherwise by physical or sensory impairments. ${ }^{3-6)}$ In addition in this study learning difficulty was defined in children as academic achievement below average compared to their classmates avarage academic achievement (based on their last semester report card which showed the average academic class achievement) where there was no obvious history of physical, sensory and intellectual function impairment. A medical history interview and basic physical examination were completed to exclude physical and sensory impairment. The intellectual functioning was defined based on a clinical psychiatric interview using Diagnostic and Statistical Manual of Mental Disorders-IV-Text Revision (DSM-IV-TR) criteria for mental retardation.

Our research subjects were primary school students from the first to the 6th grade in a public elementary school. The inclusion criteria were; (1) grade one to 6 elementary school students; (2) no chronic physical illness as reported by the parents; (3) no severe mental disorder, such as, psychotic disorder, severe depression, or other mood disorders. Mentally retarded children were excluded.

The second stage was the case-control study $(n=230)$ which calculated the odds ratio of working memory deficit in students with learning difficulties. All children with learning difficulty and working memory deficit from the first stage were included in this stage $(n=58)$. Controls were children without any learning difficulty who came from a similar school, class, age and gender. We collected 3 controls for each case $(n=172)$. The inclusion criteria for the controls were: (1) no learning learning difficulty; (2) grade one to 6 elementary school students; (3) no chronic physical illness as reported by the parents; (4) no severe mental disorder, such as, psychotic disorder, severe depression, or other mood disorders.

The authors did a psychiatric interview with parents and children using the Mini Neuropsychiatric Interview for children (MINI-Kid) to exclude psychiatric disorders. The MINI-Kid has been translated into the Indonesian language by the Division of Child and Adolescent Psychiatry, Department of Psychiatry, University of Indonesia. 
To fulfill the sample size, we selected 30 primary schools by proportional random sampling throughout Jakarta, but only 27 primary schools ultimately participated in this study. Research subjects were randomly selected from the 27 schools respectively. We used $p<0.05$ as the reference for significance.

\section{Instruments}

Working Memory Rating Scale (WMRS) was used to determine the working memory deficits in children from 5-11 years old. It was developed by Alloway et al. ${ }^{9)}$ and consists of 20 questions. This can be used by teachers and other professional educators who are teaching children in the classroom for at least a month. Every question is answered by; not typical (0), occasionally (1), fairly typical (2), or very typical (3).

WMRS has been validated in the Indonesian language in 2011. The cut off value is determined based on T-score and divided into 2 categories; (1) for children age from 6-9 years old (sensitivity $=0.161$ and speficity $=0.674$ ), and (2) for children age from 10-12 years old (sensitivity $=0.186$ and speficity $=0.929$ ). T score $>60$ shows moderate working memory deficit and $\mathrm{T}$ score $>70$ shows severe working memory deficit. The classroom teacher was asked to fill out the Indonesian version of the WMRS. Cronbach's alpha score 0.959 with 20 items scored. The correlation among items ranged from 0.189 to 0.777 . Test-retest reliability test with Wilcoxon-rank test indicated no significant difference between the WMRS assessment on the first and third month $(p=0.950)$. We also obtained demographic data for the students and parents.

Before being enrolled in the study, parents and teachers were asked to complete an informed consent. All data was computed and analyzed using SPSS for graduate student version 16 (SPSS Inc., Chicago, IL, USA).

\section{RESULTS}

In the first stage study, the age range among our sample $(n=423)$ was 5-15 years, and the mean (standard deviation) age was 9.34 (1.78). The ratio between male and female student was $6: 5$. Thirteen point seven percentage of children $(n=58)$ had learning difficulty. The mean of age of students with a learning difficulty was 9.58 (1.76). Among these 58 students with learning difficulty, 34 $(8.04 \%)$ had working memory deficit. The mean age of children with learning difficulties and working memory deficit was 9.76 (1.81) and the proportion of boys and girls

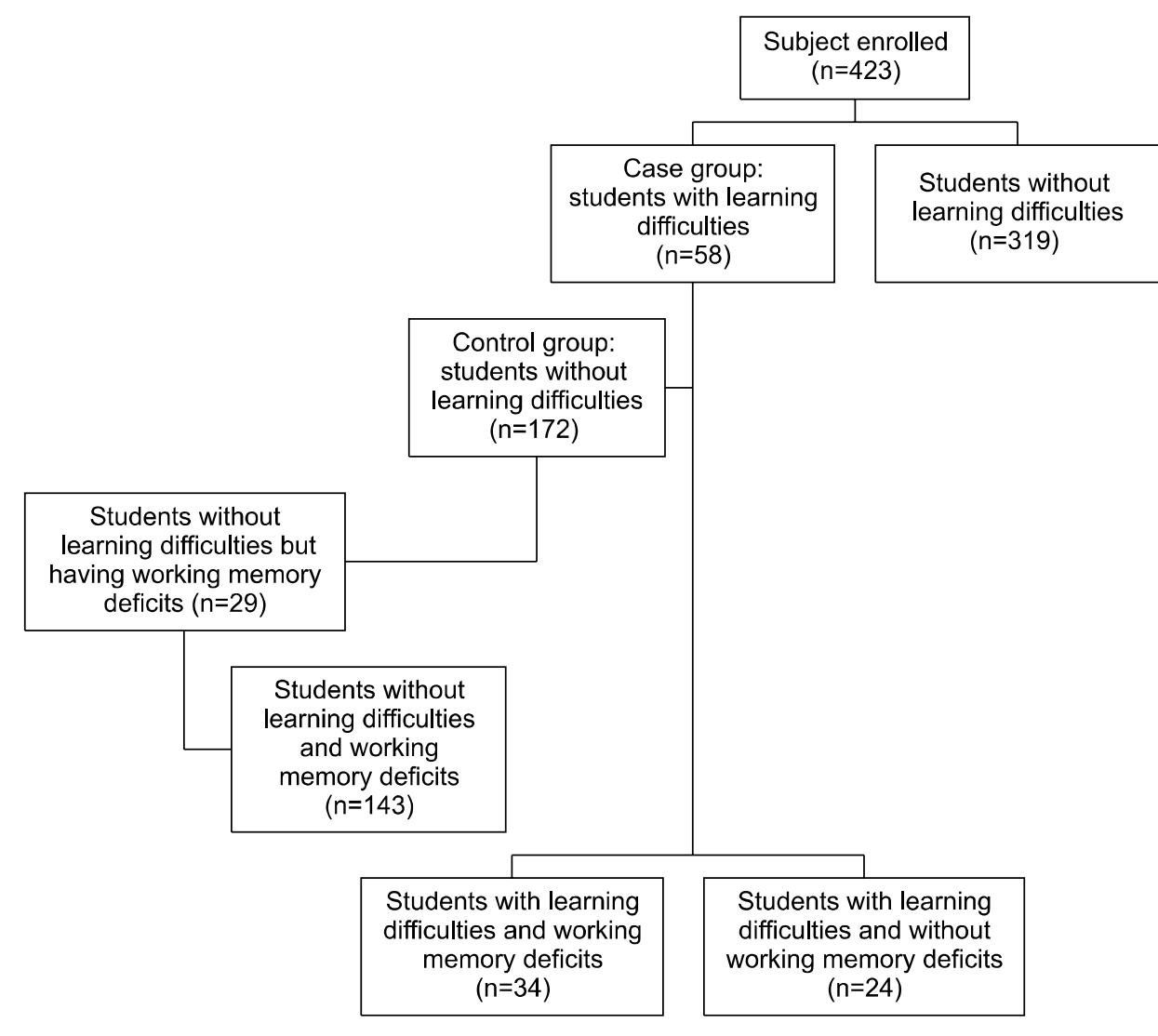

Fig. 1. The pathway of the research and the odd's ratio of the working memory deficits in children with learning difficulties was $7.0\left(X^{2}=\right.$ 35.96, $p<0.001)$. 
Table 1. Research subjects characteristics $(n=423)$

\begin{tabular}{lcc}
\hline \multicolumn{1}{c}{ Characteristics } & $\begin{array}{c}\text { Total } \\
(\mathrm{n}=423)\end{array}$ & $\begin{array}{c}\text { Subjects with } \\
\text { learning difficulty } \\
(\mathrm{n}=58)\end{array}$ \\
\hline Age (year) & $5-15$ & $7-14$ \\
Range & $9.34(1.78)$ & $9.82(1.79)$ \\
Mean (SD) & & $p=0.09^{*}$ \\
Sex, $\mathrm{n}(\%)$ & $229(54.1)$ & $31(53.5)$ \\
Male & $194(45.9)$ & $27(46.5)$ \\
Female & & $p=0.89^{\dagger}$ \\
Paternal ethnicity, $\mathrm{n}(\%)$ & $174(41.1)$ & $17(29.3)$ \\
Javanese & $60(14.2)$ & $10(17.2)$ \\
Sundanese & $10(2.4)$ & $2(3.4)$ \\
Bataknese & $95(22.5)$ & $11(19.0)$ \\
Betawinese & $4(0.9)$ & $1(1.70)$ \\
Ambonese & $80(18.9)$ & $17(29.3)$ \\
Others & $\mathrm{n}(\%)$ & $7(12.1)$ \\
Parental socioeconomic status & & \\
Low & $30(7.1)$ & $5(8.6)$ \\
Middle & $369(87.2)$ & \\
High & $24(5.7)$ & $(79.3)$ \\
\hline Mann-Whitney & & \\
\hline
\end{tabular}

*Mann-Whitney U Test; 'Fisher's Exact Test.

$\mathrm{SD}$, standard deviation.

was not any different $(p=0.78)$ (Fig. 1 , Table 1$)$.

In the case-control study, there was no significant difference in age or gender between the case and control group. The case group ranged in age from 7-14 years old and the control group ranged in age from 6-13 years old. There was a significant difference in the mean of the WMRS between the case and control group (Table 2). The odds ratio of working memory deficit in children with learning difficulty was $7.0\left(X^{2}=35.96 ; p<0.001\right)$. Thus, children with working memory deficit had seven times the risk for having difficulty in learning compared to children without a working memory deficit.

\section{DISCUSSION}

In this study $13.7 \%$ of primary school student aged 6-12 years old in Jakarta had a learning difficulty and 8.04\% had a learning difficulty with working memory deficit. These results differed significantly from a previous study of learning difficulty in elementary students who came to the Child Development and Child Psychiatric Clinic which showed a prevalence of $28 \%{ }^{14)}$ It could be understood that children who were coming to the clinic already had mental health problems or mental illness which impacted the daily functioning including their capacity to learn and social interaction.

The study findings showed that learning difficulties
Table 2. Characteristic of case-control research subjects $(n=230)$

\begin{tabular}{lccc}
\hline Characteristic & $\begin{array}{c}\text { Student with } \\
\text { learning difficulty } \\
(n=58)\end{array}$ & $\begin{array}{c}\text { Student without } \\
\text { learning difficulty } \\
(n=172)\end{array}$ & $p$ value \\
\hline Age (year) & $7-14$ & $6-13$ & \\
$\begin{array}{l}\text { Range } \\
\text { Mean (SD) }\end{array}$ & $9.82(1.79)$ & $9.48(1.63)$ & $p=0.281^{*}$ \\
Gender, $n$ (\%) & & & $p=0.540^{\dagger}$ \\
Male & $31(53.5)$ & $71(41.3)$ & \\
Female & $27(46.5)$ & $101(58.75)$ & \\
WMRS score, & $29.17(15.66)$ & $11.50(11.05)$ & $p=0.000^{*}$ \\
mean (SD) & & & \\
Working memory deficit, $n(\%)$ & & \\
No & $24(41.4)$ & $143(83.1)$ & \\
Moderate deficit & $16(27.6)$ & $21(12.2)$ & \\
Severe deficit & $18(31)$ & $8(4.7)$ & \\
\hline
\end{tabular}

*Mann-Whitney U-Test, ${ }^{\dagger}$ chi-square test.

SD, standard deviation.

among primary school students is a serious mental health problem. Learning difficulties led to distress and often to expulsion from school because the children could not meet the expectations of the class. Parents reported that these children were lazy or unintelligent, and were often stigmatized and labeled as being naugthy students. In fact, many of these students had good intellectual functioning and were capable. ${ }^{17)}$ Parents usually feel frustration dealing with this condition because they were not well informed on how to manage it, and often left the problem unsolved.

This study revealed that intellectual functioning alone could not predict that students would learn well. It seemed that working memory deficit played an important part in the learning difficulty that led to school failure. Action should be taken to help these children to continue their education by implementing an assessment of working memory for children seen as having a learning disability.

Multiple activities are said to be useful for children with learning difficulties and working memory deficits. Promoting their curiosity and guiding them to take notes while trying to learn was effective. Verbal working memory can be stimulated through word, alphabet, and sentence play. Playing with shapes, pictures, and numbers will develop visuo-spatial working memory. Instruments or activities designed for use on a computer can attract a child's interest. Several kinds of teaching techniques can support a child's capacity to learn. Among these techniques are the use of pictures to help memorize a story; asking a child to retell the story chronologically from their memory; using words, such as, first, second, and next to demarcate sections; and stimulating a child to recognize the missing 
numbers in a sequence: $0,1,2, \ldots, 4,5,{ }^{18,19)}$

There were important limitations in this study, such as not including other risk factors which potentially might affect the learning abilities and working memory deficits, for example, nutritional status, learning styles, and also the home environment which may affect the student's learning capabilities. In addition, the definition of learning difficulty which was used in this study might not be a universal definition but only used in this study. Only a clinical psychiatric interview was used, based on the DSM-IV-TR criteria, to exclude mental retardation but did not examine IQ which might also affect the sample selection both in case and control group.

On the other hand, this study is the first study which trying to identify the prevalence of learning difficulties and working memory deficits in primary school age children in Indonesia. Additionally, the number of research subjects in this study was quite large and randomly selected which might be representative for the primary school children population in Jakarta or other big cities in Indonesia.

This study revealed that working memory deficit is a significant risk factor that highly impacts learning capacity in children. Parents and teachers should acknowledge this condition and learn the methods that might be used to help overcome these difficulties.

\section{REFERENCES}

1. Harrison PL, Flanagan DP. Contemporary intellectual assessment: theories, tests, and issues. New York:The Guilford Press;2005. p.597.

2. Lerner JW. Learning disabilities: theories, diagnosis, and teaching strategies. 8th ed. Boston: Houghton Mifflin; 2000.

3. Child Development Institute. About learning disabilities [Internet]. Orange, CA: Child Development Institute; 2008 [cited 2010 Dec 2]. Available from: http://www.childdevelopmentinfo.com/learning/learning_disabilities.shtml

4. Selekman J. Learning disabilities: a diagnosis ignored by nurses. Pediatr Nurs 2002;28:630-632.

5. Alloway TP. Working memory but not IQ predicts subsequent learning in children with learning difficulties. European J Psychol Assess 2009;25:92-98.
6. Alloway TP, Alloway RG. Investigating the predictive roles of working memory and IQ in academic attainment. $J$ Exp Child Psychol 2010;106:20-29.

7. Colom R, Abad FJ, Quiroga MA, Shih PC, Mendoza CF. Working memory and intelligence are highly related constructs, but why? Intelligence 2008;36:584-606.

8. Tsatsanis KD. Psychological and neuropsychological assessment of children. In: Martin A, Volkmar F, editors. Lewis's child and adolescent psychiatry. A comprehensive textbook. 4th ed. Philadelphia:Wolters Kluwer Health/Lippincott Williams \& Wilkins;2007. p.357-370.

9. Alloway TP, Gathercole SE, Kirkwood H, Elliot J. The working memory rating scale: a class room-based behavioral assessment of working memory. Learn Individ Differ 2009; 19:242-245.

10. Science Daily. Children's under-achievement could be down to poor working memory [Internet]. Rockville, MD: Science Daily; 2008 [cited 2010 Dec 6]. Available from: http:// www.sciencedaily.com/releases/2008/02/080227205111.htm

11. Wiguna T, Wibison S, Sastroasmoro S. The effect of longacting methylphenidate $20 \mathrm{mg}$ in improving clinical symptoms of ADHD. Sari Pediatri 2010;2:142-148.

12. Fletcher JM, Reid Lyon G, Barnes MA, Fuchs LS. Learning disabilities: from identification to intervention. New York: The Guilford Press;2007. p.324.

13. Olive T. Working memory in writing: empirical evidence from the dual-task technique. European Psychologist 2004; 9:32-42.

14. Wiguna T, Manengkei P, Pamela C, Rheza A, Hapsari W. Emotional and behavioral problems among children and adolescent in child and adolescent out-patient clinic Cipto Mangunkusumo General Hospital, Jakarta. Sari Pediatri 2010;12:270-277.

15. Kellogg RT, Olive T, Piolat A. Verbal, visual, and spatial working memory in written language production. Acta Psychol (Amst) 2007;124:382-397.

16. McCuthen D. Knowledge, processing, and working memory: Implications for a theory of writing. Educational Psychologist 2000;35:13-23.

17. Wiguna T, Belfer ML. Awareness, understanding and help seeking for behavior problems by parents of primary school age children in Central Jakarta: a qualitative study in the community. Pediatr Indones 2010;50:18-25.

18. Holmes J, Gathercole SE, Dunning DL. Adaptive training leads to sustained enhancement of poor working memory in children. Dev Sci 2009;12:F9-F15.

19. Jaeggi SM, Buschkuehl M, Jonides J, Perrig WJ. Improving fluid intelligence with training on working memory. Proc Natl Acad Sci U S A 2008;105:6829-6833. 